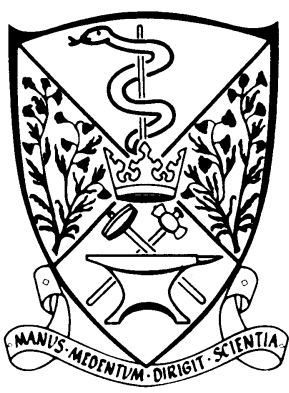

\section{Pyruvate kinase deficiency}

\author{
Association with G6PD deficiency
}

Pyruvate kinase deficiency was first described in 1961 by Valentine et al.' Since then it has emerged as the second most common red cell enzyme defect after glucose 6-phosphate dehydrogenase deficiency. Well over 300 cases have been reported worldwide, predominantly in people with a North European ancestry. ${ }^{2}$ It is, however, a rare disease, with an estimated prevalence of less than 1 in 10000 .

\section{Case history}

An 18 month old girl from Oman presented to our hospital in July 1989 for further investigation of congenital anaemia. She had been born at full term by spontaneous vaginal delivery. A few hours after birth jaundice was noted. Her haemoglobin concentration at birth was $98 \mathrm{~g} / \mathrm{l}$ with a reticulocytosis of $21 \%$. Her serum bilirubin concentration was raised at $300 \mu \mathrm{mol} / \mathrm{l}$. She was treated with exchange blood transfusion and discharged home, but was readmitted four weeks later with recurrent anaemia.

Further investigations in Oman failed to find the cause of her anaemia. She was therefore started on regular red cell transfusions and required about $300 \mathrm{ml}$ every two months. She grew and developed normally. Family history showed that her parents were first cousins; she had three siblings, all of whom were alive and well, and there had been one stillborn male child.

On examination she looked well, her height was on the 90th centile, and her weight was on the 50th centile. She had hepatosplenomegaly: the liver was $4 \mathrm{~cm}$ and the spleen $3 \mathrm{~cm}$ below the costal border.

Results of laboratory investigations carried out five weeks after her last blood transfusion gave the following results: haemoglobin concentration $117 \mathrm{~g} / \mathrm{l}$, mean cell volume $82 \mathrm{fl}$, mean corpuscular haemoglobin $27.3 \mathrm{pg}$, mean corpuscular haemoglobin concentration $0 \cdot 29$, reticulocytes $1.6 \%$, white blood cell count $9.4 \times 10^{9} / 1$, platelet count $358 \times 10^{9} / 1$. The red cell glucose 6-phosphate dehydrogenase activity was $5 \cdot 4 \mathrm{U} / \mathrm{g} \mathrm{Hb}$ (normal range $7 \cdot 2-12 \cdot 8 \mathrm{U} / \mathrm{g} \mathrm{Hb}$ ) and the red cell pyruvate kinase activity was $5 \cdot 4 \mathrm{U} / \mathrm{g} \mathrm{Hb}$ (normal range $6 \cdot 2-14 \cdot 2 \mathrm{U} / \mathrm{g} \mathrm{Hb}$ ). Liver function tests gave normal results. The blood film showed the presence of a large number of normal red cells, which were probably transfused. In addition, occasional poikilocytes were present (fig 1). Bone marrow examination showed increased erythroid activity, but the marrow was otherwise normal. Haemoglobin electrophoresis showed an $\mathrm{A}$ and $\mathrm{C}$ band. This was intriguing because neither of her parents had haemoglobin $\mathrm{C}$. The $\mathrm{C}$ band was quantitated at $31 \%$. Her recent blood transfusion precluded a conclusive diagnosis. She returned to Oman where she continued to receive periodic blood transfusions.

In June 1990 the infant returned to the hospital for review and further investigation. She had been well in the preceding 11 months and her growth and development remained normal. Her last red cell transfusion had been three months previously. On examination she was pale and had hepatosplenomegaly, as previously noted.

On this occasion investigations showed a haemoDr Stephen Gilbey.
Series edited by:

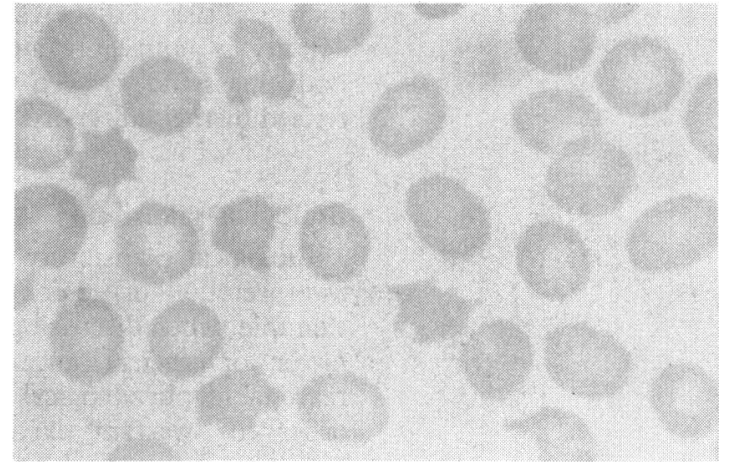

FIG 1-Blood film showing typical prickle cells in patient with pyruvate kinase deficiency

globin concentration of $47 \mathrm{~g} / \mathrm{l}$, mean cell volume $104.8 \mathrm{fl}$, mean corpuscular haemoglobin $33.7 \mathrm{pg}$, mean corpuscular haemoglobin concentration $0 \cdot 29$, reticulocytes $20 \%$, white blood cell count $9 \cdot 3 \times 10^{9} / 1$, and platelet count $338 \times 10^{9} / 1$. Her blood film showed macrocytosis, polychromasia, and occasional spiculated cells. Repeat haemoglobin electrophoresis showed only an $\mathrm{A}$ and an $\mathrm{A}_{2}$ band, confirming that the $\mathrm{C}$ band detected previously originated from transfused cells. Her serum bilirubin concentration was mildly increased at $27 \mu \mathrm{mol} / \mathrm{l}$. Her serum ferritin concentration was increased at $467 \mathrm{mg} / \mathrm{l}$.

An acidified serum lysis test to exclude paroxysmal nocturnal haemoglobinuria gave negative result and an osmotic fragility test normal result. We then carried out an autohaemolysis test. The principle of this test is to measure the extent of haemolysis that takes place when defibrinated blood is incubated under sterile conditions for 48 hours. With most intrinsic red cell abnormalities appreciable haemolysis occurs in the absence of glucose. When the abnormality is in the membrane there is usually complete or substantial correction of the haemolysis when the sample is supplemented with glucose. This is described as a type I pattern. When the abnormality is in a glycolytic enzyme glucose does not correct the autohaemolysis since it cannot be used efficiently because of a metabolic block. This is known as a type II pattern. Our patient had $6 \%$ lysis without glucose and 5.5\% lysis with glucose (a control patient had $0.9 \%$ and $0.1 \%$ lysis without and with glucose). Her results are clearly of a type II pattern.

The table shows glucose 6-phosphate dehydrogenase and pyruvate kinase activities in June 1990 and July 1989. Glucose 6-phosphate dehydrogenase activity was significantly lower in June 1990 than in July 1989; presumably the earlier value was caused by transfused

Glucose 6-phosphate dehydrogenase and pyruvate kinase activities of patient with haemolytic anaemia and normal ranges

\begin{tabular}{lccc}
\hline & $\begin{array}{c}\text { July } \\
1989\end{array}$ & $\begin{array}{c}\text { June } \\
1990\end{array}$ & $\begin{array}{c}\text { Normal } \\
\text { range }\end{array}$ \\
\hline $\begin{array}{l}\text { Glucose 6-phosphate dehydrogenase } \\
\text { (U/g Hb) }\end{array}$ & $5 \cdot 4$ & $0 \cdot 7$ & $7 \cdot 2-12 \cdot 8$ \\
Pyruvatc kinase (U/g Hb) & $5 \cdot 4$ & $4 \cdot 5$ & $6 \cdot 2 \cdot 14 \cdot 2$ \\
\hline
\end{tabular}


red cells. The pyruvate kinase activity, however, remained relatively unchanged.

Study of the patient's close relatives (fig 2) showed that the family carried the genes not only for glucose 6-phosphate dehydrogenase and pyruvate kinase deficiency but also for $\beta$ thalassaemia. The $\beta$ thalassaemia gene was present in the patient's mother and in one sister.

Our patient had both glucose 6-phosphate dehydrogenase and pyruvate kinase deficiency. In principle her haemolytic anaemia might have resulted from either of the two enzymopathies or from a combination of both; DNA analysis showed that her glucose 6-phosphate dehydrogenase deficiency was the common Mediterranean type, ${ }^{3}$ and this variant does not cause chronic haemolysis, although it can cause acute haemolytic episodes when the patient is exposed to oxidant drugs, infections, or fava beans. In summary, our patient had a congenital haemolytic anaemia due to pyruvate kinase deficiency. In addition, she had coexistent glucose 6-phosphate dehydrogenase deficiency.

\section{Comment}

Pyruvate kinase deficiency is transmitted as an autosomal recessive trait, and because of its rarity most affected patients probably have inherited two different mutant allelic genes. However, a consanguineous marriage can result in a true homozygote, as presumably occurred in our patient.

Pyruvate kinase is one of the key enzymes of the red cell glycolytic pathway. It is a tetramer composed of

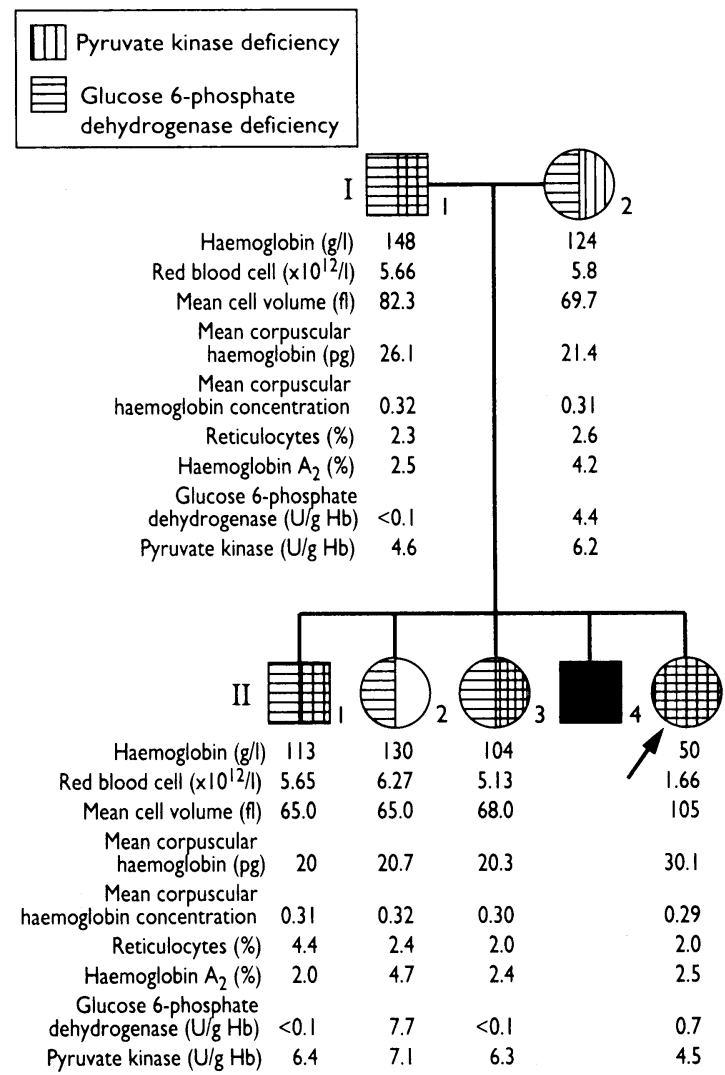

FIG 2-Pedigree of patient's family showing segregation of pyruvate kinase deficiency, glucose 6-phosphate dehydrogenase deficiency, and $\beta$ thalassaemia. The patient is indicated by arrow. Subjects $I-1, I I-1$ and II-3 are homozygous for glucose 6-phosphate dehydrogenase deficiency and heterozygous for pyruvate kinase deficiency; subject I-2 is heterozygous for both pyruvate kinase deficiency and glucose 6phosphate dehydrogenase deficiency; subject II-2 is heterozygous only for glucose 6-phosphate dehydrogenase deficiency; and subject II-5 is homozygous for both glucose 6-phosphate dehydrogenase deficiency and pyruvate kinase deficiency. Segregation of $\beta$ thalassaemia is seen from the high $A_{2}$ level in $I-2$ and II-2 but not in $I I-1,113-5$ identical $60 \mathrm{kDa}$ subunits. Pyruvate kinase converts phosphoenolpyruvate to pyruvate (fig 3), and when the enzyme is deficient the ATP concentration in red cells is often decreased and the 2,3-diphosphoglycerate concentration increased. Valentine et al suggested that ATP depletion is the crucial factor responsible for haemolysis in pyruvate kinase deficiency. ${ }^{2}$

The presentation and severity of disease varies widely among patients with pyruvate kinase deficiency. Most patients present in infancy or childhood with anaemia or jaundice. Sometimes, however, the condition is so mild that it is not diagnosed until adulthood. The anaemia is generally severe to moderate (haemoglobin concentration ranging from 40 to $100 \mathrm{~g} / \mathrm{l}$ ) but is usually well tolerated, perhaps in part due to the increased 2,3-diphosphoglycerate concentration and a consequent shift of the oxygen dissociation curve to the right. Clinical jaundice is common at presentation and, like the anaemia, it may be exacerbated during infection. ${ }^{2}$ Aplastic crises are rare but have been documented with parvovirus infections. ${ }^{5}$ Neonatal jaundice is not uncommon and exchange transfusions may be required. Gall stones are a common consequence of the hyperbilirubinaemia.

Splenomegaly is mild to moderate; unlike in $\beta$ thalassaemia skeletal changes are rare. Further rare complications include kernicterus in the neonatal period, chronic leg ulcer, acute pancreatitis secondary to biliary tract disease, development of iron overload, and splenic abscesses. ${ }^{26}$

The diagnosis can be suspected from a combination of the history and the blood film, which shows macrocytes and bizarre "prickle" or "sputnik" cells. However, the proof can be obtained only by performing a spectrophotometric pyruvate kinase assay. Affected homozygotes were originally thought to have enzyme activities of $5-20 \%$ of the normal mean. However, there are both technical and biological problems with the assay. Firstly, as white cells have 10-100 times more pyruvate kinase activity than red cells, blood must be depleted of white cells before the assay is performed. Secondly, because a mutant enzyme must have altered kinetics it is important to carry out the assay at different substrate concentrations. Patients may have pyruvate kinase activity close to or within the normal range and yet the red cells may be functionally pyruvate kinase deficient because the substrate affinity is adversely affected by the mutation. There is poor correlation between pyruvate kinase activity and clinical severity, which is illustrated by the fact that some asymptomatic heterozygous patients have pyruvate kinase values within the homozygous range. ${ }^{2}$

No specific treatment exists for pyruvate kinase deficiency. Supportive treatment in severe cases consists of regular red cell transfusions with iron chelation and folic acid. Despite the encouraging results obtained with bone marrow transplantation in $\beta$ thalassaemia ${ }^{7}$ the risks presently associated with the procedure make it unsuitable for most patients with pyruvate kinase deficiency.

Splenectomy may be valuable in some patients who require regular transfusions. Patients who have had splenectomy should take life long penicillin prophylaxis, and patients living in or travelling to malarious areas should take antimalarial prophylaxis.

\section{Discussion}

LL: This family shows the need to disentangle both technical and biological problems in the differential diagnosis of a congenital haemolytic anaemia. Patients quite often have to be investigated after transfusion, and in our patient the availability of blood free of transfused red cells was crucial to prove that haemoglobin $\mathrm{C}$ was a red herring and that she did not have 


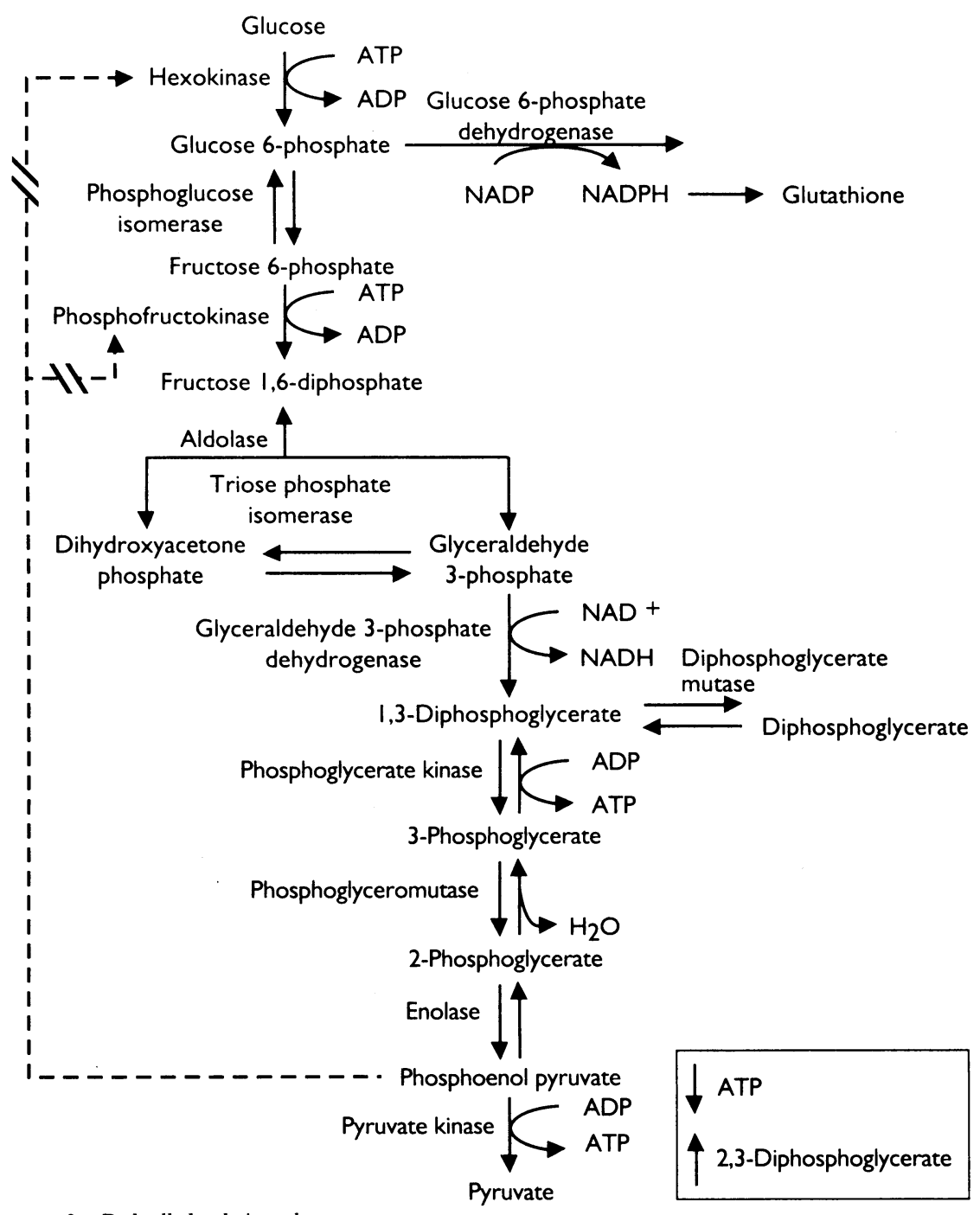

FIG 3-Red cell glycolytic pathway

$\beta$ thalassaemia, although it was present in the family. We were able to conclude that the patient had a combination of glucose 6-phosphate dehydrogenase deficiency and pyruvate kinase deficiency. To my knowledge only one other case has been reported. ${ }^{8}$

SRB: I was a bit confused that the pyruvate kinase activity was similar in the child and parents yet you are saying that the child is a homozygote and the parents are heterozygotes. Can you be sure of that?

LL: This is a valid question and reflects a common source of difficulty in diagnosing pyruvate kinase deficiency. In fact, a family study is often crucial because the pyruvate kinase activity in the patient is greatly affected by the reticulocyte count. The pyruvate kinase activity in heterozygotes (who have no haemolysis and therefore a normal reticulocyte count) is nearly $50 \%$ of normal, depending on the particular pyruvate kinase variant. In a person who is not pyruvate kinase deficient with $15 \%$ reticulocytes pyruvate kinase activity would be about twice normal. The finding of reduced pyruvate kinase activity in the presence of reticulocytosis is almost always suspicious of deficiency and when corroborated by family studies as in this case I would regard it as conclusive.

SRB: Is it possible to say whether glucose 6-phosphate dehydrogenase has contributed to the overall haemolysis in this patient?

LL: The only way of confirming whether the two abnormalities interact would be for the parents of our patient to have another child who was homozygous for pyruvate kinase deficiency but not glucose 6-phosphate dehydrogenase deficient. We could then compare the degree of haemolysis in the two patients. In the absence of this biological test, I think it would be prudent to assume that pyruvate kinase deficiency is solely responsible for this patient's chronic non-spherocytic haemolytic anaemia. Glucose 6-phosphate dehydrogenase deficiency of the Mediterranean type by itself causes acute haemolysis only in combination with an exogenous trigger.

CTD: Would bone marrow transplantation have been an option?

LL: Our patient's haemolytic anaemia seems to be sufficiently severe to warrant consideration of bone marrow transplantation. The potential risks and benefits would have to be carefully assessed by ourselves and the parents. However, since she does not have an HLA compatible sibling this was not an option at the time.

SRB: How many isozymes of pyruvate kinase are there?

PM: Four different pyruvate kinase isozymes have been described in humans: L (liver), $R$ (red cell), and M1 and M2 (muscle). In the mature erythrocyte only the $\mathrm{R}$ isozyme is present.

CTD: Have any advances been made in identifying the molecular defect in pyruvate kinase deficiency?

LL: The normal chromosomal DNA has been isolated and sequenced recently, ${ }^{9}$ and one mutation has been identified in a patient with a chronic nonspherocytic haemolytic anaemia.

CTD: What treatment has been recommended for this patient?

LL: Splenectomy because we ${ }^{4}$ and others have found that it may reduce, and in some cases eliminate, transfusion requirement, although there is no guarantee that it will do so in every case.

CTD: Should the patient take life long antimalarial prophylaxis, living in Oman?

LL: Yes, and this has been recommended.

1 Valentine WN, Tanaka KR, Miwa S. A specific erythrocyte glycolytic enzyme defect (pyruvate kinase) in 3 subjects with congenital non-spherocytic anemi. Trans Assoc Am Physians 1961:74:100-10.

2 Valentine WN, Tanaka KR, Paglia DE. Pyruvate kinase and other enzyme deficiency disorders of the erythrocyte. In: Scriver CR, Beaudet AH, Sly W, Valle D, eds. The metabolic basis of inherited disease. Vol 6. New York: McGraw-Hill, 1989:2342-8.

3 Kurdi-Haidar B, Mason PJ, Berrebi A, Ankra-Bada G, Al-Ali A, Oppenheim $A$, et al. Origin and spread of the glucose-6-phosphate dehydrogenase varian (G6PD-Mediterranean) in the Middle East. Am f Hum Genet 1990;47:1013-9. 4 Luzzatto L. Inherited haemolytic anaemia. In: Hoffbrand AV, Lewis SM, eds. Postgraduate haematology. 3rd ed. Oxford: Heinemann, 1988:146-86.

5 Dacie J. The hereditary enzyme deficiency hemolytic anemia 1. In: The hereditary hemolytic anemias. 3rd ed. New York: Churchill Livingstone, 1985:282-313.

6 Tanaka KR, Zerez CR. Red cell enzymopathies of the glycolytic pathway. Semin Hematol 1990;27:165-85.

7 Lucarelli G, Galimberti M, Polchi P, Angelucci E, Baronciani D, Giardini D, et al. Bone marrow transplantation in patients with thalassemia. $N$ Englf Med 1990;322:417-21.

8 Zanella A, Colombo $M$, Mintero R, Perroni L, Miloni T, Sirchia G. Erythrocyte pyruvate kinase deficiency-11 new cases. Br 7 Haematol 1988:69:399-404.

9 Kanno H, Fujit H, Hirono A, Miwa S. cDNA cloning of human R-type pyruvate kinase and identification of a single amino acid substitution affecting enzymatic stability in a pyruvate kinase variant (PK Tokyo) associated with hereditary hemolytic anemia. Proc Natl Acad Sci USA 1991;88:8218-21. 